\title{
Chemical decellularization: a promising approach for preparation of extracellular matrix
}

\author{
Hana Hrebikova, Daniel Diaz, Jaroslav Mokry
}

\begin{abstract}
Background. A biological scaffold from extracellular matrix can be produced by a variety of decellularization methods whose caveat consists in efficiently eliminating cells from the treated tissue. This scaffold can be used in diverse applications for tissue engineering and organ regeneration. Preservation of the extracellular matrix ultrastructure is highly desirable because of its unique architecture, contained growth factors and decreased immunological response. All of these properties provide attachment sites and adequate environment for cells colonizing this scaffold, reconstituting the decellularized organ. This review briefly describes chemical decellularization methods, evaluation of these protocols and the role of ECM in tissue engineering.
\end{abstract}

Conclusion. Chemical decellularization is an often used method for scaffold preparation and makes possible a wellpreserved three dimensional structure of extracellular matrix.

Key words: chemical decellularization, detergent, extracellular matrix, cell lysis

Received: March 25, 2013; Accepted with revision: September 24, 2013 Available online: October 18, 2013 http://dx.doi.org/10.5507/bp.2013.076

Department of Histology and Embryology, Medical Faculty in Hradec Kralove, Charles University in Prague, Simkova 870, Hradec Kralove Corresponding author: Jaroslav Mokry, mokry@lfhk.cuni.cz

\section{INTRODUCTION}

Decellularized tissues have become widely used in regenerative medicine and some of them are even commercially available, mostly in the USA ${ }^{1-5}$ (for example, human skin removed from cadavers which is supplied in dry form and commonly used in cases of third degree burn patients $\left.{ }^{1,2}\right)$. The combination of physical, chemical and biological techniques provide the means for more efficient elimination of cellular and nuclear components, preservation of blood vessels' stroma and nerve pathways. The obtained decellularized matrix is complex in structure, functional protein composition, glycosaminoglycan content and growth factors. This extracellular matrix (ECM) can then be used as a scaffold, which can be colonized by cells with regenerative properties (e.g. pluripotent cells, embryonic stem cells, umbilical cord cells, mesenchymal cells etc.). The scaffold maintains its original graft size and shape after implantation. An added benefit of decellularization is the elimination of immunologically active molecules, therefore leading to reduced transplant rejection rates.

General decellularization protocols commonly begin with physical cell lysis, chemical or biological methods. Physical methods often involve changing temperature conditions that lead to intracellular ice crystal formation which disrupt the cell membrane. Other possible decellularization methods using physical conditions are highpressure treatments. High pressure treated tissues undergo cell lysis and also eliminate viruses and bacteria. Physical methods are commonly used for tissue decellularization of tissues such as pericardium ${ }^{6}$, larynx ${ }^{7}$, bone marrow ${ }^{8}$, cornea $^{9}$ or blood vessels ${ }^{10}$.

\section{CHARACTERIZATION OF EXTRACELLULAR MATRIX}

The extracellular matrix is structurally complex and diverse in its composition of functional proteins, glycoproteins and proteoglycans which are organized into a three-dimensional system. These characteristics provide elasticity, binding sites for cell surface receptors and signal factors to the ECM, which are essential for angiogenesis, cell migration and proliferation ${ }^{11}$.

ECM properties are a result of its specific protein content. For instance, collagen is the most abundant protein within the ECM, and though over 20 different types of collagen have been reported, in ECM only types I, III, IV, VI and VII are commonly found ${ }^{12}$. Collagen type I is a well conserved protein; therefore, it has become a good source for tissue engineering scaffolds. Other collagen types, such as collagen VI, are essential for mechanical and physical properties or provide gel like consistency to the ECM. Hence, ECM is source of several collagen types that are able to provide proper environment for tissue reconstruction.

Fibronectin, is another protein present in ECM although it is more commonly found in submucosal structures and basement membranes of tissues. This type of protein plays a major part in cell adhesion by ligand presentation $^{13}$. Fibronectin can be used as a coating protein in synthetic scaffold material. Laminin, which can also be found in the ECM, is typically localized to its basement membrane and its inherent properties confer good adhesion characteristics to the scaffold.

Growth factors present in the ECM are also necessary for successful tissue reconstruction ${ }^{14}$. Decellularized 
scaffolds contain diverse growth factors such as VEGF (important for vessel formation), bFGF (stimulates cell proliferation and has a crucial role in differentiation), KGF (necessary for epithelialization of wounds) among others, that are present in small but sufficient amounts for tissue regeneration.

The original concept of ECM passivity in tissue development was reconsidered with the discovery of dynamic reciprocity between the ECM and intracellular cytoskeletal and nuclear elements. The ECM has a major role in the differentiation of myoblast to myotubes ${ }^{15}$; also, the main structural component of ECM (collagen) is important for the development of salivary glands ${ }^{16}$. This knowledge has become useful in tissue engineering, since it allowed the use of ECM as a scaffold for tissue reconstruction by applying cells with differentiation and proliferation potential.

ECM components are highly conserved and well tolerated among different species. This fact was confirmed when performing organ transplantation experiments; for example, heart valves ${ }^{17,18}$, blood vessels ${ }^{10,19}$, skin $^{20}$ and muscles $^{21}$.

\section{METHODS OF DECELLULARIZATION}

A commonly used technique in decellularization involves the combination of chemical and physical methods. The most effective decellularization processes include a combination of physical, chemical and enzymatic agents. However, the final result is dependent on factors such as tissue cellularity, density, lipid content and so on ${ }^{22}$.

\section{Alkaline and acid treatments}

Acid and basic treatments cause the hydrolysis of cytoplasmic components and the degradation of nucleic acids; however, it could have adverse effects on glycosaminoglycan content. Peracetic acid is a frequently used acid agent, as it has a most efficient result when performing whole organ perfusion of lipid tissues ${ }^{23}$ without degrading it and also preserving any present growth factors in the tissue. In addition, peracetic acid is utilized for its antiseptic properties, and is also capable of eliminating DNA from the treated tissue ${ }^{24}$.

Basic agents are usually harsh on the treated tissue and are therefore commonly used to remove hair from dermal samples before starting the decellularization process. These harsh properties can have damaging effects on the ECM and their application can have adverse side effects on the collagen fibres, whose outcome could end in decreased ECM mechanical properties ${ }^{25}$.

\section{Hypertonic and hypotonic treatments}

The use of either hypotonic or hypertonic solutions promotes cell lysis by osmotic shock, and also results in the disruption of DNA-Protein interactions. However, these solutions are not able to completely eliminate cells from the treated tissue ${ }^{22}$. It is a common assumption that the persistence of original cellular material in the scaffold can induce a deteriorating effect over the graft healing process and subsequent graft rejection. In order to achieve decreased cellular debris presence, it is common practice to rinse the tissue with hyper- or hypotonic solutions for several cycles. Tris $\mathrm{HCl}$, EDTA and $\mathrm{NaCl}$ solutions are the most frequently used treatments.

\section{Non-ionic detergents}

Non-ionic detergents are widely used in decellularized protocols because of their mild effect upon tissue architecture and their high efficiency in cell removal. They disrupt interactions between lipid-lipid and lipid-protein, while keeping protein-protein interactions intact ${ }^{25}$.

Triton X-100 (octyl phenol ethoxylate) is the most frequently used non-ionic detergent in decellularized protocols and it is applied mostly for thin tissues such as heart valves, blood vessels and ligaments. The exposure time of tissues to Triton X-100 can vary among different protocols, ranging in time from $6 \mathrm{~h}$ to 14 days $^{26-28}$. Different periods of exposure have different decellularization results. Despite of this, Triton X-100 causes minimal changes in ECM composition; on the other hand, it decreases the amount of glycosaminoglycans (GAG) in the ECM (ref. ${ }^{29}$ ). Triton X-100 also appears to be the best agent for elimination of lipids from the treated tissues ${ }^{22}$.

\section{Ionic detergents}

SDS (sodium dodecyl sulfate) solubilizes cell membranes, but tends to denature proteins by disrupting their reciprocal interactions ${ }^{25}$. SDS, as a decellularization agent, seems to be more effective than Triton X-100 since its effectiveness is higher, especially with dense organs such as kidney, liver or temporomandibular joints $\mathrm{s}^{30-32}$. On the other hand, SDS has deleterious effects upon the amount of GAG in the ECM. This, in itself, decreases the mechanical stability of the scaffold ${ }^{25,33}$.

SDS has a different incubation time from Triton $\mathrm{X}-100$, being more effective in $24 \mathrm{~h}$ incubation periods at $0.1-1 \%$ concentration ${ }^{20,34,35}$.

\section{Zwitterionic detergents}

CHAPS or 3-[(3-cholamidopropyl) dimethylammonio]1-propanesulfonate combines the properties of non-ionic and ionic detergents. As confirmed by histological analyses, CHAPS is ideal for thin tissues such as peripheral nerves $^{36,37}$, blood vessels ${ }^{38}$ or lungs ${ }^{39}$. It also has proved to be non-damaging to collagen and elastin structures. However, it also promotes decreased mechanical properties to the scaffold, which are comparable with those caused by treatments with Triton X-100 or hypertonic solutions.

\section{Alcohols \\ Alcohols remove lipids from tissue very effectively and cause tissue dehydration leading to cell lysis. However, the use of either methanol or ethanol promotes protein pre- cipitation; therefore, their use is limited to the elimination of phospholipids from tissue, since the preservation of phospholipids in the tissue could cause calcification ${ }^{40,41}$;}


usually, a combination of methanol with chloroform is used.

It is worth keeping in mind that any residual chemical agents present in the ECM after decellularization could have cytotoxic effects on colonizing cells. In order to achieve a complete removal of these residues, several washing cycles with PBS are used.

\section{Biological decellularization}

Biological agents such as proteolytic enzymes, are used in combination with chelating agents and nucleases in decellularization methods ${ }^{20,42}$.

Trypsin proteolysis is widely used in decellularization of heart valves ${ }^{41}$ or dermis ${ }^{20}$. However, the stability of extracellular components is limited against trypsin and its use could induce undesired alterations in collagen, elastin or GAG content ${ }^{43}$. It is therefore recommended to utilize it for short periods of time to prevent damage against the basic components of ECM. On the other hand, the harsh characteristics of trypsin can be used for membrane disruption, increasing the efficiency of subsequent decellularization treatments ${ }^{44}$.

\section{DECELLULARIZATION TECHNIQUES}

Each kind of tissue has specific structure and different composition, so it is not possible to use only one standard protocol for each type of tissue (Table 1). The choice of decellularization agent to be applied depends on the type of tissue to be treated ${ }^{45}$ as well as of its composition

Table 1. Example of decellularization protocols ${ }^{22}$.

\begin{tabular}{ll}
\hline Thin laminates (pericardium) & 1) freeze \\
& 2) osmotic solutions \\
& 3) enzyme \\
& 4) acid or base \\
\hline Thicker laminates (dermis) & 1) freeze \\
& 2) enzyme \\
& 3) alcohol \\
& 4) acid or base \\
& 5) detergent \\
\hline Fatty, amorphous tissues & 1) freeze \\
& 2) mechanical disruption \\
& 3) alcohol \\
& 4) enzymatic \\
& 5) acid or base \\
& 6) alcohol \\
\hline Whole organ decellularization & 1) freeze \\
(trachea) & 2) osmotic solutions \\
& 3) detergent \\
& 4) enzymatic \\
5) osmotic solutions \\
\hline Whole organ decellularization & 1) freeze \\
(liver) & 2) osmotic solutions \\
& 3) detergent \\
4) osmotic solutions & 5) detergent \\
\hline
\end{tabular}

(thickness, density of tissue). Apparently, the most effective method is the use of immersion/agitation and wholeorgan perfusion processes.

\section{Agitation and immersion}

Principle of decellularization by means of agitation/ immersion is a two-step process: the sample tissue is immersed in decellularization solution (e.g. SDS) followed by its agitation in an orbital shaker, allowing the solution to permeate through the tissue. Thinner tissues (such as urinary bladder) can be effectively decellularized after a short incubation with peracetic acid, which disrupts its surface tissue without the need for agitation ${ }^{22}$.

In addition, agitation can also be used for rinsing residual detergents, by means of PBS washing cycles. It may be used for heart valves ${ }^{28}$, muscles ${ }^{46}$, peripheral nerves ${ }^{47}$, trachea $^{48}$ and dermis ${ }^{49}$.

\section{Whole organ perfusion}

Perfusion seems to be a more effective decellularization method, since this method able to preserve tissue vasculature; also, it's more efficient in the delivery of decellularization agents inside the tissue and able to wash out cellular debris. Whole organ perfusion is used for tissue such as heart ${ }^{27,50}$, liver ${ }^{26,32}$, lungs ${ }^{35}$ or bladder ${ }^{51}$. The organs are previously cannulated to ease the access of decellularization solutions. A previous study described liver decellularization ${ }^{31}$ by means of whole organ perfusion with SDS, proving to be an effective method since the tissue was completely decellularized and the ECM's composition and structure remained intact. Subsequently, the tissue was recellularized with hepatocytes, thus providing evidence on the preservation of ECM components able to support cell colonization.

\section{DECELLULARIZATION EFFECT ON THE ECM}

Any decellularization process can affect the 3D structure of the extracellular matrix; for instance, glycosaminoglycans could be depleted, losing any water molecules bound to it and leading to decreased tissue elasticity. Some detergents can induce alterations in the collagen fibers resulting in decreased mechanical stability of the tissue $^{52,53}$.

\section{EVALUATION OF DECELLULARIZED ECM}

Standard evaluation methods for decellularized ECM include histological analyses, immunohistochemistry, biochemical analyses, DNA/GAG quantification, hydroxyproline assay, 2D electrophoresis among others. The concept of "decellularization" has not yet been described in terms of quantitative metrics; however, it can be said (upon the findings of other studies) that decellularized tissue could be defined as follows: it should contain no 

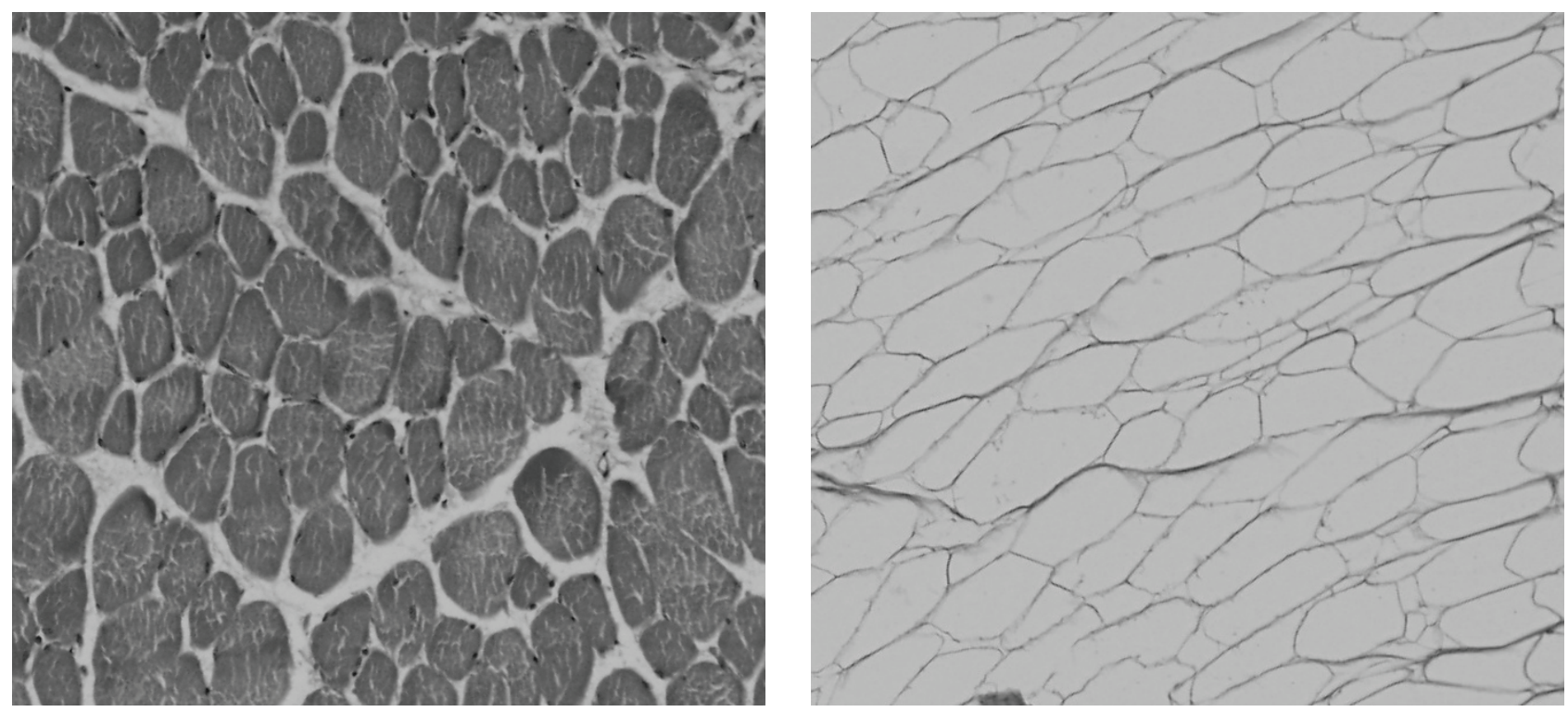

Fig. 1. Comparison between physiological tissue (murine muscle tissue) stained with hematoxyline-eosin and decellularized tissue after $24 \mathrm{~h}$ incubation with $1 \%$ sodium dodecyl sulfate.

more than 50 ng of DNA per mg of extracellular matrix, any present DNA should be in fragments less than $200 \mathrm{bp}$ in length and the ECM should lack any visible nuclear material as confirmed by standard hematoxylin or DAPI staining ${ }^{22}$.

Hematoxylin-eosin staining is the standard technique for basic histological inspection and analysis. Although alternative staining methods can be used, such as Masson's trichrome or Movat's pentachrome, to examine the presence of cytoplasmic or extracellular molecules. The presence of DNA molecules can be detected by DAPI staining or BrdU assay.

Immunohistochemistry is also used to determine the presence or absence of extracellular proteins e.g. laminin, fibronectin, collagen or GAG. We could also use Western blot for this purpose since it has similar principle.

DNA quantification can be determined by spectrophotometric analysis, measuring DNA concentration by means of fluorometric stains, e.g. ethidium bromide or Hoechst, which are incorporated into the structure of DNA. Stained DNA is then exposed to a specific UV radiation wavelength $\left(\mathrm{A}_{260 \mathrm{~nm}}\right)$; the resulting emitted radiation rate is directly proportional to the concentration of nucleic acids in the sample.

Proline is an essential aminoacid that can be found in hydroxylated form in tissues; its quantification is commonly used as a standard reference for protein degradation measurement, e.g. collagen or elastin. Quantification of hydroxyproline is carried out by lysing the samples with hydrochloric acid, which then will react with p-dimethylaminobenzaldehyde, and later analysed by spectrophotometry. Color intensity determines the concentration of hydroxyproline present in the analysed sample. The results of this test indicate if the decellularization process was too harsh on either collagen or elastin structure.

Electrophoresis is a basic separative method for proteins, using the distribution of molecules on a synthetic matrix based on their molecular weight and charge in electrical field as an analysis tool. SDS-PAGE (sodium dodecyl sulfate polyacrylamide gel electrophoresis) is the most commonly used gel electrophoresis technique used for proteins. One study, focused on decellularization of skin $^{19}$; SDS-PAGE was used as an evaluation tool and the results showed that decellularization was effective since collagen did not show any alterations.

\section{CONCLUSION}

Extracellular matrix (ECM), as a biologic scaffold derived from a process of decellularization, can be used in regenerative medicine. The main objective of decellularization is the preservation of ECM's three-dimensional structure which consists of structural and functional proteins, glycosaminoglycans, growth factors, etc. ECM is an immunologically inert scaffold that preserves the native vascular and neural network of the source material and can be utilized in tissue engineering. The efficiency of the decellularization process is dependent upon several factors such as tissue density and organization, decellularization method, biologic components and targeted clinical applications. The combination of physical, chemical and biological methods provides a better outcome regarding cell removal. The development of an optimal decellularization protocol is a major concern and one still persisting in tissue engineering and regenerative medicine.

\section{ABBREVIATION}

BrdU, 5-bromo-2'-deoxyuridine; DAPI, 4',6-diamidino-2-phenylindole; ECM, Extracellular matrix; GAG, Glycosaminoglycans; CHAPS, 3-[(3-cholamidopropyl) dimethylammonio]-1-propanesulfonate; SDS, Sodium dodecyl sulphate. 


\section{ACKNOWLEDGEMENT}

This study was supported by grants from Internal Competition of Medical Faculty in Hradec Králové, programme PRVOUK P37/06, Grant of the Charles University in Prague No. SVV-2012-264901 and No. 736213. Publication is co-financed by the European Social Fund and the state budget of the Czech Republic. Project no. CZ.1.07/2.3.00/30.0022.

Authorships contribution: HH: literature search, manuscript writing, data collection; DD: literature search; JM: final corrections and approval.

Conflict of interest statement: The authors state that there are no conflicts of interest regarding the publication of this article.

\section{REFERENCES}

1. Wainwright D. Use of an acellular allograft dermal matrix (AlloDerm) in the management of full-thickness burns. Burns 1995;21(4):243-48.

2. Misra S, Raj PK, Tarr SM, Treat RC. Results of AlloDerm use in abdominal hernia repair.Hernia 2008;12(3):247-50.

3. Badylak, SF. Xenogeneic extracellular matrix as a scaffold for tissue reconstruction. Transpl Immunol 2004;12(3-4):367-7.

4. Kolker AR, Brown DJ, Redstone JS, Scarpinato VM, Wallack MK. Multilayer reconstruction of abdominal wall deffects with acellular dermal allograft (AlloDerm) and component separation. Ann Plast Surg 2005;55(1):36-42.

5. Parker DM, Armstrong PJ, Frizzi JD, North JH. Porcine dermal collagen (Permacol) for abdominal wall reconstruction. Curr Surg 2006:63(4):255-8.

6. Aimoli CG, Noguiera GM, Nascimento LS, Baceti A, Leirner AA, Maizato MJ, Higa OZ, Polakiewicz B, Pitombo RN, Beppu MM Lyophilized bovine pericardium treated with a phenethylaminediepoxide as an alternative to preventing calcification of cardiovascular bioprosthesis: preliminary calcification results. Artif Organs 2007;31(4):278-3.

7. Hung $\mathrm{SH}$, Su CH, Lee FP, Tseng H. Larynx decellularization: combining freeze-drying and sonication as an effective method. J Voice 2013;27(3):289-94.

8. El-Sabban ME, El-Khoury H, Hamdan-Khalil R, Sinder-Pedersen S Bazarbachi A. Xenogenic bone matrix extracts induce osteoblastic differentiation of human bone marrow-derived mesenchymal stem cells. Regen Med 2007;2(4):383-90.

9. Hashimoto $Y$, Funamoto $S$, Sasaki $S$, Honda T, Hattori $S$, Nam K, Kimura T, Mochizuki M, Fujisato T, Kobayashi H, Kishida A Preparation and characterization of decellularized cornea using high-hydrostatic pressurization for corneal tissue engineering Biomaterials 2010;31(14):3941-8.

10. Funamoto $S$, Nam K, Kimura T, Murakoshi A, Hashimoto $Y$, Niwaya K, Kitamura S, Fujisato T, Kishida A. The use of high-hydrostatic pressure treatment to decellularized blood vessels. Biomaterials 2010;31(13):3590-5.

11. Badylak SF. The extracellular matrix as a scaffold for tissue reconstruction. Semin Cell Dev Biol 2002;13(5):377-83.

12. Vanderrest M, Garrone R. Collagen family of proteins. FASEB J 1991;5(13):2814-23.

13. Schwarzbauer JE. Fibronectin: from gene to protein. Curr Opion Cell Biol 1991;3(5):786-91.

14. Perniconi B, Costa A, Aulino P, Teodori P, Adamo S, Coletti D. The pro-myogenic environment provided by whole organ-scale acellular scaffolds from skeletal muscle. Biomaterials 2011;32(31):7870-7882.

15. Hauschka SD, Konigsberg IR. The influence of collagen on the development of muscle clones. Proc Natl Acad Sci 1966;55(1):119-26.

16. Wessells NK, Cohen JH. Effects of collagenase on developing epithelia in vitro: Lung, ureteric bud and pancreas. Dev Biol 1968;18(3):294309.

17. Bader A, Schilling T, Teebken OE. Tissue engineering of heart valve human endothelial cell seeding of detergent acellularized porcine valves. Eur J Cardiothorac Surg 1998;14(3):279-84.
18. Booth C, Korossis SA, Wilcox HE, Watterson KG, Kearney JN, Fisher J, Ingham E. Tissue engineering of cardiac valves prostheses I: development and histological characterization of an acellular porcine scaffold. J Heart Valve Dis 2002;11(4):457-62.

19. Conklin BS, Richter ER, Kreutziger KL, Zhong DS, Chen C. Development and evaluation of a novel decellularized vascular xenograft. Med Eng Phys 2002;24(3):173-83.

20. Chen RN, Ho HO, Tsai YT, Sheu MT. Process development of an acellular dermal matrix (ADM) for biomedical applications. Biomaterials 2004;25(13):2679-86.

21. Wolf MT, Daly KA, Reing JE, Badylak SF. Biologic scaffold composed of skeletal muscle extracellular matrix. Biomaterials 2012;33(10):29162925.

22. Crapo P, Gilbert TW, Badylak SF. An overview of tissue and whole organ decellularization processes. Biomaterials 2011;32(12):3233-43.

23. Kosaraju RS. The future of tissue engineering: A novel perfusionbased protocol for decellularizing adipose tissue on a bioreactor. Proceedings of the California State Science Fair California State Science Fair; 2011 2-3 May; California, USA.

24. Gilbert TW, Freund J, Badylak SF: Quantification of DNA in biologic scaffold materials. J Surg Res 2009;152(1):135-9.

25. Gilbert TW, Selaro TL, Badylak SF. Decellularization of tissues and organs. Biomaterials 2006;(27)19:3675-83.

26. Baptista MP, Siddiqui MM, Lozier G, Rodriguez SR, Atala A, Soker S. The use of whole organ decellularization for the generation of a vascularized liver organoid. Hepatology; 2011;53(2):604-17.

27. Ott CH, Mathiesen TS, Goh SK, Black LD, Kren SM, Netoff TI, Taylor D. Perfusion-decellularized matrix: using nature's platform to engineer a bioartificial heart. Nature Medicine 2007;14(2):213-21.

28. Wang L, Johnson JA, Chang DW, Zhang Q. Decellularized musculofascial extracellular matrix for tissue engineering. Biomaterials. 2013;34(11):2641-54

29. Grauss RW, Hazekamp MG, Oppenhuizen F, Munsteren CJ, Gitenberger-de Groot AC, DeRuiter MC. Histological evaluation of decellularised porcine aortic valves: matrix changes due to different decellularisation methods. Eur J Cardiothorac Surg 2005;27(4):56671.

30. Nakayama KH, Batchelder CA, Lee Cl, Tarantal AF. Decellularized rhesus monkey kidney as a three-dimensional scaffold for renal tissue engineering. Tissue Eng Part A 2010;16(7):2207-16.

31. Lumpkins SB, Pierre N, McFetrigde PS. A mechanical evaluation of three decellularization methods in the design of a xenogeneic scaffold for tissue engineering the temporomandibular joint disc. Acta Biomater 2008;4(4):808-16.

32. Uygun BE, Soto-Gutierrez A, Yagi $H$, Izamis ML, Guzzardi MA Shulman C, Milwid J, Kobayashi N, Tilles A, Berthiaume F, Hertl M, Nahmias $Y$, Yarmush ML, Uygun K. Organ reengineering through development of a transplantable recellularized liver graft using decellularized liver matrix. Nat Med 2010;16(7):814-20.

33. Courtman DW, Pereira CA, Kashef V, McComb D, Lee JM, Wilson GJ. Development of a pericardial acellular matrix biomaterial: biochemical and mechanical effects of cell extraction. J Biomed Mater Res 1994;28(6):655-66.

34. Uzarski JS, Van de Walle AB, McFetridge PS. Preimplantation processing of ex vivo-derived vascular biomaterials: effects of peripheral cell adhesion. J Biomed Mater Res A 2013;101(1):123-31.

35. Cebotari S, Tudorache I, Jaekel T, Hilfiker A, Dorfman S, Ternes W, Haverich A, Lichtenberg A. Detergent decellularization of heart valves for tissue engineering: toxicological effects of residual detergents on human endothelial cells. Artif Organ 2010;34(3):206-10.

36. Hudson TW, Zawko S, Deister C, Lundy S, Hu CY, Schmidt CE. Optimized acellular nerve graft is immunologically tolerated and supports regeneration. Tissue Eng 2004;10(11-12):1645-51.

37. Hudson TW, Liu SY, Schmidt CE. Engineering an improved acellular nerve graft via optimized chemical processing. Tissue Eng 2004;10(9-10):1346-58.

38. Dahl SL, Koh J, Prabhakar V, Niklason LE. Decellularized native and engineered arterial scaffolds for transplantation. Cell Transplant 2003;12(6):659-66.

39. Wallis JM, Borg ZD, Daly AB, Deng B, Ballif AF, Allen GB, Jaworski DM, Weiss DJ. Comparative assessment of detergent-based protocols for mouse lung de-cellularization and re-cellularization. Tissue Eng Part C Methods 2012;8(6):420-32.

40. Levy RJ, Vyavahare N, Ogle M, Ashworth P, Bianco R, Schoen FJ. Inhibition of cusp and aortic wall calcification in ethanol- and al- 
uminium-treated bioprosthetic heart valves in sheep: background, mechanism, and synergism. J Heart Valve Dis 2003;12(2):209-16.

41. Clark JN, Ogle MF, Ashworth P, Bianco RW, Levy RJ. Prevention of calcification of bioprosthetic heart valve cusp and aortic wall with ethanol and aluminium chloride. Ann Thorac Surg 2005;79(3):897904.

42. Schenke-Layland K, Vasilevski O, Opitz F, König K, Rieman I, Halbhuber KJ, Wahlers T, Stock UA. Impact of decellularization of xenogeneic tissue on extracellular matrix integrity for tissue engineering of heart valves. J Struct Biol 2003;143(3):201-8.

43. Yang M, Chen CZ, Wang XN, Zhu YB, Gu YJ. Favourable effects of the detergent and enzyme extraction method for preparing decellularized bovine pericardium scaffold for tissue engineered heart valves. J Bio Mater Res B Appl Biomater 2009;91(1):354-61.

44. Yang B, Zhang Y, Zhou L, Sun Z, Zheng J, Chen Y, Dai Y. Development of a porcine bladder acellular matrix with well-preserved extracellular bioactive factors for tissue engineering. Tissue Eng Part $C$ Methods 2010;16(5):1201-11.

45. Freytes DO, Stoner RM, Badylak SF. Uniaxial and biaxial properties of terminally sterilized porcine urinary bladder matrix scaffolds. J Biomed Mater Res B Appl Biomater 2008;84(2):408-14.

46. Gillies AR, Smith LR, Lieber RL, Varghese S. Method for decellularizing skeletal muscle without detergents or proteolytic enzymes. Tissue Eng Part C Methods 2011;17(4):383-9.
47. Karabekmez FE, Duymaz A, Moran SL. Early clinical outcomes with use of decellularized nerve allograft for repair sensory defects within the hand. Hand 2009;4(3):245-9.

48. Baiguera S, Jungebluth $P$, Burns A, Mavilia C, Haag J, De Coppi $P$, Macchiarini $P$. Tissue engineered human tracheas for in vivo implantation. Biomaterials 2010;31(34):8931-8.

49. Reing JE, Brown DN, Daly KA, Freund JM, Gilbert TW, Hsiong SX, Huber A, Kullas KE, Tottey S, Wolf MT, Badylak SF. The effects of processing methods upon mechanical and biologic properties of porcine dermal extracellular matrix scaffolds. Biomaterials 2010;31(33):8626-33.

50. Weymann A, Loganathan S, Takahashi H, Schies S, Claus B, Hirsberg K, Soós P, Korkmaz S, Schmack B, Karck M, Szabó G. Development of and evaluation of a perfusion decellularization porcine heart model. Circ Journal 2011;75(4):852-60.

51. Consolo F, Brizzola S, Tremolada G, Grieco V, Riva F, Acocella F, Fiore GB, Soncini M. A dynamic distention protocol for whole-organ bladder decellularization: Histological and biomechanical characterization of the acellular matrix. J Tissue Eng Regen Med. 2013;4:1767.

52. Woods T, Gratzer PF. Effectiveness of three extraction techniques in the development of a decellularized bone-anterior cruciate ligament-bone graft. Biomaterials 2005;26(35):7339-49.

53. Cartmell JS, Dun MG. Effect of chemical treatments on tendon cellularity and mechanical properties. Tissue Eng 2000;49(1):134-40. 